\title{
Access to Quality Education for Students with Disability
}

\author{
Luke Macaulay \\ Monash University, Faculty of Education \\ Joanne Deppeler \\ Monash University, Faculty of Education \\ Joseph Agbenyega \\ Monash University, Faculty of Education
}

\section{Abstract}

Conceptualising educational equity and academic achievement is a key task for inclusive education and the politics of inclusion. Recent Australian Government reports (2013-2016) on educational access and inclusion report low levels of educational access and attainment for students with disability. This paper considers the place that Pierre Bourdieu's critical social theory has in helping us to conceptualise access, equity, and inclusion, and argue that the concepts of habitus, capital, and field (Bourdieu, 1977) have a key role to play in this process. Utilising these concepts to draw closely on three recent Australian Government reports (2013-2016) on educational equity and inclusion, our analysis has identified three consistent themes across these reports which disadvantage students with disability. These include cultural issues, economic capital, and the utility of education. These themes compound and culminate to highlight an issue of a lack of continuity across the field of education within Australia. As a consequence, the value of capital and operation of habitus function inconsistently across the field, rendering the process of the acquisition of success as being inequitable. Consideration is given to the need for a careful rethinking of how the inclusive education concept, connected to politics, can be transformed to eradicate inequities and inconsistencies to the benefit of all.

Keywords: inclusive education, Australia, disability, disadvantage, Bourdieu

Access to quality education is associated with social and economic opportunity, future prosperity, and is viewed as a fundamental right within democratic societies (Artiles, 2015; Balfanz \& Fox, 2011). However, studies suggest that students with disability are most vulnerable in terms of educational achievement, school completion, and employment opportunities (UNESCO, 2015a, 2015b, 2014).

For example, Carter, Austin, and Trainor (2012) found that students with disability in the United States often achieve levels of educational attainment which are inadequate to secure meaningful employment. These findings are in dissonance with the United States' Individuals with Disabilities Education Improvement Act (IDEA) (2004) which states that a key role of education is to "prepare... [students] for further education, employment, and independent living" (p. 6). Mitra, Posarac, and Vick (2013) claim similar results have been demonstrated in developing countries and state, "in most countries, disability is found to be significantly

Corresponding author: Luke Macaulay (luke.macaulay@monash.edu) 
associated with higher multidimensional poverty as well as lower educational attainment [and] lower employment rates" (p. 1). The situation appears to be no different in Australia. Recent evidence identifies that students with disability in Australia have low levels of educational access and attainment which in turn produce "long-lasting and severe problems for them, their families, and the entire Australian society" (Education and Employment References Committee, 2016, p. 4).

In this paper we have utilised document analysis strategies in combination with Pierre Bourdieu's (1977) concepts of habitus, capital, and field to analyse three recent Australian Government reports which address levels of educational inclusion for students with disability. We have identified three core themes across these documents relative to the field of education which hinder genuine educational inclusion for these students. These are cultural issues, economic capital, and the utility of education. Together these themes appear to contribute to a lack of continuity across the field of education, creating barriers to genuine inclusive education for students with disability.

According to O'Rourke (2015), effective inclusive education establishes and augments educational opportunities for students with disability because each student is treated as a valued member of the school's community. Schools in which students with disability are not considered or treated as full members often face learning barriers in the pursuit of educational inclusion (Education and Employment References Committee, 2016). Genuine educational inclusion recognises these barriers and strives for their removal (UNESCO, 2016; Mittler, 2012; Ainscow, Dyson, Goldrick, \& West, 2011). Slee (2008) highlights, "[mainstream] schools were not an invention for all and subsequently the struggle with demands for broadening participation is more profound than is widely acknowledged" (p. 99). There appears to be a persistent presence of relations of power, which maintain the status quo, creating educational barriers for some students with little mainstream public resistance (Education and Employment References Committee, 2016; O'Rourke, 2015; Kenway, 2013).

While the specific focus of this paper is on students with disability, the ideas underpinning the discussions within this paper have relevance to a number of students who are vulnerable to educational disadvantaged due to their social and/or cultural background. It is important to note however, disadvantage and social and cultural backgrounds are not intrinsically linked, "being disadvantaged is not a quality of people, it is a feature or an outcome of what happens to some young people by virtue of their experiences in some of our institutions" (Lamb, Jackson, Walstab, \& Huo, 2015, p. 3). The social structures and institutional context of education has historically viewed students from certain social and cultural backgrounds as different; a cultural other from normal (Artiles, 2011; Slee, 2001; Gillborn \& Youdell, 2000). This difference comes with the consequence of disadvantage, whereby "being different heightens one's vulnerability to injustice" (Artiles, 2015, p. 1).

Disability, gender, sexuality, socio-economic status, race, ethnicity, and indigeneity are all enduring examples of constructed categories vulnerable to the process of othering within certain social and institutional contexts (Artiles, 2015; Lamb et al., 2015; Slee, 2001; Gillborn \& Youdell, 2000). It is commonplace for students to be identified in more than one of these groups compounding their disadvantage (Artiles, 2015; Lamb et al., 2015; Gonski et al., 2011). Furthermore, it is unexceptional, and has been for decades, for these groups to be overrepresented within the special education context. (Miles, 2016; Skiba, Artiles, Kozleski, Losen, \& Harry, 2015; Graham, 2012). This can be argued to be due to the process of othering, whereby those constructed as being different or the other are excluded and placed on the margins of the mainstream (Slee, 2013; Graham \& Slee, 2008). At the core of inclusive education however is the principle that the structures of education should be 
orientated in a manner to remove barriers that institutionally marginalise certain students (Forlin \& Chambers, 2013). Thereby, it is important to note that the practice of inclusive education is not solely focused on the educational inclusion of students with disability.

\section{Conceptualising inclusive education}

Conceptualising and subsequently defining inclusive education is a difficult and contentious task (Loreman et al., 2014). O'Rourke (2015) argues that definitions can guide practice, and as such, issues in the defining of inclusive education go beyond mere semantics. Conceptualisation precedes definition in the gestational stage of a concept or idea. However, it may be argued this process is reversed once a concept or idea (such as inclusive education) has been defined and attempted to be actualised in a concrete sense (i.e. how we define concepts determines how we conceptualise and enact these concepts). This is problematic, for in the absence of a clear definition and framework of what is meant when discussing inclusive education, misinterpretations can occur circumventing Australian legislation and policy (Australian Research Alliance for Children and Youth (ARACY), 2013; Education and Employment References Committee, 2016).

Australia has an obligation and commitment to genuine educational inclusion for all students via conventions, policies, and legislation operating at international, national, and state and territory levels (e.g. United Nations [2006] Convention on the rights of persons with disability; Commonwealth of Australia [2006] Disability Standards for Education 2005). However, these vary in how they can be interpreted as defining inclusive education. For example, there is a tendency in many countries, including Australia, to interpret inclusive education as an issue of educational inclusion solely relative to disability (ARACY, 2013). However, as highlighted by Forlin and Chambers (2013), inclusive education is driven by an education for all philosophy "that considers the needs of any potentially marginalised students" (p. 6). Failure to grasp this point is also a failure to grasp the complexities inherent to issues of equity within inclusion, such as the commonality of marginalised students belonging to multiple groups who are at risk of institutional disadvantage. The difficulties in defining inclusive education has led to a dissonance between policy and practice; with little or clear references to guide practice (ARACY, 2013).

Whilst definitions of inclusive education vary, Loreman et. al. (2014) contend that definitions of inclusive education can usually be grouped into two categories. The first group of definitions conceptualises inclusive education based on what key features exist in the form of opportunities for students. This conception of inclusive education is problematic however, for it may become outdated with shifts in culture and practice. Furthermore, this conception assumes the existence of global commonalities relative to inclusive education and implies a one size fits all approach, leaving little room for cultural and practical variations across regions and nations (Loreman et. al., 2014).

The second group of definitions conceptualises inclusive education based on identifying and removing barriers and practices which exclude certain students from educational access and attainment. This conception of inclusive education is stronger than the first as it is socially and culturally adaptable. Its weakness however is that it defines inclusive education in the negative by stating what it is not rather than what it is. This considered, UNESCO's (2016) definition of inclusive education, which fits into this second category, is highly defensible relative to other proposed definitions. This definition is as follows:

"Education is not simply about making schools available for those who are already able to access them. It is about being proactive in identifying the barriers and obstacles learners encounter in attempting to access opportunities for quality 
education, as well as in removing those barriers and obstacles that lead to exclusion" (para. 1).

The strength and usefulness of UNESCO's definition is that it recognises the dynamic nature of society whilst explicitly recognising operations of inequities therein. Definitions of this sort are adaptable to change, and to social and cultural variations within the complex and dynamic nature of society.

\section{Conceptualising inclusive education through a Bourdieuian lens:}

Bourdieu's social theory recognises the complex and dynamic nature of society within which education and institutional practices of inclusive education operate across varying fields (Agbenyega et. al., 2015). Bourdieu (1977) uses the term fields to refer to "dynamic, concrete, political, social and symbolic institutions such as the family, law and education" (DiGiorgio, 2009, p. 183). The field of education, according to Bourdieu, is an arena of both structured and structuring practices that produce different types of experiences for different individuals. Structured practices depict traditional static forms of beliefs, values, and norms often associated with primitive societies. Whilst on the other hand, the notion of structuring practices highlights the ability of societies to reify dominant ideologies, which create hierarchies of power to assert and maintain social control over various members of the community (Wacquant, 1989). This highlights the complexities and potential inconsistencies of how success is achieved across the intricate landscape of society and education. Within the field of education, which is situated within the larger context of society, individuals who have an invested interest in the successful application of inclusive education need to have a mastery of the dominant and dynamic nuances of this field. (Sullivan, 2002). This is in order to be able to apply the rules of the field and determine the value and appropriate exchange of the capital they possess in order to achieve success (DiGiorgio, 2009).

Bourdieu (1997) conceptualises capital to be durable assets that individuals accumulate and exchange within fields in order to achieve success. The accumulation of capital within a field is influenced by exposure to habitus. Habitus is the dispositional unconscious identity of social agents. Bourdieu (1977) refers to habitus as being "systems of durable, transposable dispositions, structured structures predisposed to function as structuring structures" (p. 72). However, varying forms of capital can have varying values across fields, and the habitus of individuals within and across fields can be inconsistent. As a result, the process of determining the value of capital can be complicated by inconsistencies, thereby making the mastery of how to succeed within fields difficult. This can be conceptualised through the lens of Bourdieu's formula of habitus $x$ capital + field= Practice (Agbenyega et. al., 2015). Social practice is determined and affected by the value of capital and the operation of habitus relative to what field represents in the formula. However, if the value of capital, and operation of habitus are inconsistent across a field, the mastery of social practice becomes particularly difficult. This is especially pronounced for students with disability, who as a cohort experience high levels of social exclusion reducing their exposure to the operation of certain social practices (Australian Curriculum, Assessment and Reporting Authority (ACARA), 2012).

Bourdieu (1976) uses the analogy of a card game to describe the operation of social success. Across the field of interactions individuals are dealt cards (i.e. capital) with each card and combination of cards having differing values which people use to vie for success (Lareau \& McNamara Horvat, 1999). The value of cards and combinations of cards (i.e. capital), and the rules of the game are determined by the field in which the game is occurring. For individuals to successfully play the game they must accept the rules and the pre-determined values of the 'cards' they are 'dealt' (DiGiorgio, 2009). For individuals who 
are vulnerable to social and institutional disadvantage the 'how to' of playing the game of success is extremely important, as the consequences of not successfully playing the game may result in social disadvantage and exclusion. However, within the 'game of success', inconsistencies in the value of capital and operation of habitus across the field of education make the rules of the game extremely difficult to determine. As the acceptance of the rules of the game and the values of capital is essential to successfully play the game, many individuals face barriers in the pursuit of obtaining educational success. Due to the apparent inconsistencies in both capital and habitus across the field of education, the deck of cards appears to be stacked against students with disability in the game of success.

\section{Method}

This paper combined document analysis strategies with Pierre Bourdieu's (1977) concepts of habitus, capital, and field to interrogate and analyse three recent government reports on educational inclusion for students with disability. These reports are as follows:

- Access to Real Learning: The Impact of Policy, Funding and Culture on Students with Disability (2016), prepared by the Education and Employment References Committee for the Australian Senate.

- Inclusive Education for Students with Disability: A review of the best evidence in relation to theory and practice (2013), prepared by the Australian Research Alliance for Children and Youth (ARACY) for the Australian Government Department of Education, Employment and Workplace Relations.

- Inclusive Education for Students with Disability Part Two: A review of the nongovernment sector in Australia, authored by Forlin and Chambers (2013), prepared by the Australian Research Alliance for Children and Youth (ARACY) for the Australian Government Department of Education, Employment and Workplace Relations.

We focused our analysis on the key question: What factors are implicated in educational inclusion for students with disability as suggested by these reports? The document analysis approach provided a systematic procedure for reviewing and evaluating the selected reports (Boslaugh, 2007). The analytic procedures we adopted included the identification and selection of three relevant documents, and appraisal and synthesis of data contained in the documents. Like other analytical methods in qualitative research, we examined and interpreted the evidence in the three documents thematically in order to elicit meaning, gain understanding, and develop empirical knowledge (L. Andrews, Higgins, M. W. Andrews, \& Lalor, 2012; Doolan \& Froelicher, 2009). In the process of analysing the documents, we critically examined the purpose of the documents, those who composed the information including the information contained in them, the timing and sources of the information, and the consistency of the information across the three reports.

It is through reviewing, interpreting, and cross-analysing these secondary documents with Bourdieu's social theory that we identified three core themes across the three documents related to the field of education in Australia which hinder genuine educational inclusion for students with disability. These are cultural issues, economic capital, and the utility of education. Together, these themes appear to produce a lack of continuity across all levels of education in Australia, from the macro level of national policies all the way through to the classroom and the individual students. Determining the value of capital and the rules for 
success is consequentially extremely challenging as the variables for success are both vast and ambiguous. As stated by Stephanie Gotlib (2016, as cited in Education and Employment References Committee, 2016), Chief Executive Officer of the advocacy group Children with Disability Australia, "the chance of accessing a quality education when you are a student with a disability is likened to that of winning the lottery" (pp. 8-9). We propose that this lack of continuity across the field of education in Australia requires further research and public attention relative to low levels of educational access and attainment for students with disability.

\section{Results}

\section{Discontinuity and educational disadvantage Cultural issues:}

Our analysis of the three documents identified that cultural issues at school, community, and national levels were influencing some students' levels of educational access and attainment. The culture of the school a student with disability attends can significantly alter their education experience (Education and Employment References Committee, 2016). One of the determinants of the cultural production of inclusivity within any given school is the habitus of the key stakeholders of that school. The attitudes of a school's leader, classroom teachers, and the local community strongly influences a school's culture of inclusion. (Education and Employment References Committee, 2016; Whitburn, 2014; ARACY, 2013). Inclusivity is a lived complex process, which is continually negotiated and renegotiated in contested space and shaped by the power relationships inherent in social structures. These power relationships can determine experiences of inclusion, or alternatively, experiences of exclusion via defining the boundaries between the two (Angwin, Blackmore, \& Shacklock, 2001).

According to Bourdieu (1999), education practices occur within hierarchical social spaces (fields), with diverse and unfixed multiple versions of imagined inclusions. These imagined inclusions result from our normative classifications, which to a great extent are influenced by our cultural values, beliefs, and dispositions, which Bourdieu refers to as habitus (Bourdieu, 2000). In addition, imagined inclusions can be shaped by the recognition of the type and form of capital one possesses within a given field, for example, cultural capital determines access and participation (Bourdieu \& Wacquant, 1992; Agbenyega \& Kilbthong, 2013). Cultural capital is acquired over time and through exposure to a particular habitus, and is embodied in the practices of social agents. The culture of a school will reinforce itself via influential agents whose habitus and capital are powerful in the structural organisation of the school. Bourdieu emphasises the relational and influential nature of human habitus acquired through cultural, institutional, and historical socialisation. Within the field of education, the operation of habitus can cause vast cultural variations across sub-fields (e.g. from school to school). This can significantly alter a student's educational experience based on the simple variable of location and options of enrolment opportunities (Education and Employment References Committee, 2016). Thus, it is not the individual difference per se that excludes, but how other people within a given field classify themselves and others as belonging to or not belonging to certain educational spaces.

At a national level there is a cultural lack of awareness of the rights students with disability possess (Education and Employment References Committee, 2016). As a result, students with disability may experience discrimination from others who construct themselves as 'normal', which often leads to a process of cognitive mapping, giving rise to student categorisation as insiders or outsiders. Students with symbolic capital, that is, those with 
varying forms of capital in relation to status within social structures (DiGiorgio, 2009) are situated in a privileged position to access and participate in the education of their choice, as this form of capital elevates their social status (Bourdieu, 1995). In view of this, Bourdieu emphasises the importance of ensuring that we take into account and draw upon the structured and structuring practices of the social world or what he calls the relation of ordinary experience in our quest for developing new understandings of inclusion (Grenfell, 2012). Whilst students with disability have legal rights mandating educational inclusion, which can protect individuals from certain consequences of insider outsider categorisations, many individuals simply are unaware of these rights (Education and Employment References Committee, 2016). This lack of awareness is far reaching, with many educators, persons with disability, and the families of persons with disability being unaware of the specificities of the legal rights all children have to an equitable education irrespective of levels of ability (Education and Employment References Committee, 2016).

The act of having policy and legislation and for there to be little awareness of its specificity undermines the vision of its existence, demonstrating a cultural contradiction between policy and practice. As a result, the value of and relationship between symbolic and cultural capital relative to policy and legislation is difficult to translate and determine within a concrete field. Legislative rights may be argued to increase success and opportunity when an individual's social status may culturally decrease their symbolic capital. However, if there is a dominant cultural naivety in relation to such policy and legislation, the possession of these rights have little cultural capital value. Furthermore, families and students with disability who are aware of their rights can face significant barriers in having these rights recognised (Cumming \& Dickson, 2013; Aron \& Loprest, 2013). This is due to adversarial systems being the mode of challenging discrimination in many developed countries, including Australia (Cumming \& Dickson, 2013; Aron \& Loprest, 2013). This can put significant emotional and economic strain on students and families, with the outcomes of these proceedings being indeterminable at the outset. (Cumming \& Dickson, 2013; Education and Employment References Committee, 2016). As a result, some families and students may view the costs versus the benefits of this process as not being worthwhile. Due to these operations of cultural production, attitudes, and systems and practices there is an apparent lack of continuity between the intersection of the fields of law and education, and the intersection of policy and practice.

\section{Economic capital:}

We identified economic capital as one of the major barriers affecting access and participation of students with disability. The economic issues identified can be grouped into two categories. Firstly, there is the issue of socio-economic status and a family's economic capital relative to the field of education, and secondly there are issues surrounding the distribution of resources to increase economic capital by way of funding for schools and individuals with disability (Education and Employment References Committee, 2016; ARACY, 2013; Forlin \& Chambers, 2013). Both of these issues highlight the inequitable distribution and exchange of economic capital within the field of education. As highlighted by the Education and Employment References Committee (2016), there is a direct link between greater financial means and educational options and opportunities, creating "classes of students with disability" (p. 9). Possessing higher levels of economic capital facilitates greater educational opportunities as this form of capital is valuable within the field of education (Education and Employment References Committee, 2016). For example, families with high levels of financial means are able to access educational support services and assistance with greater ease. Furthermore, high levels of economic capital are often associated with high levels of cultural capital (usually acquired via educational and cultural resources), which is also of great value within the field of education (Sullivan, 2007; 
DiGiorgio, 2009). As outlined by Sullivan (2002), Bourdieu argues the possession of cultural capital in relation to the field of education endows the individual with a familiarity of the structures of this field, in particular the ability to utilise purposive language competently. This is particularly useful for families who need to advocate on behalf of their child. These factors are worrying, as the possession of economic capital, and the capabilities of families to bear the costs associated with educational access and attainment differ significantly, highlighting inequities across the field of education (Education and Employment References Committee, 2016).

All states and territories in Australia recognise the need for government assistance for some students in the form of funding (ARACY, 2013). However, "currently funding for students with disabilities is inadequate" (Autism Spectrum Australia (Aspect), 2016, as cited in Education and Employment References Committee, 2016, p. 47). This appears to be further compounded by national inconsistencies across the field of education relative to the eligibility criteria for funding. This seems to be linked to inconsistent and ineffective policy decisions. For example, as highlighted by ARACY (2013), funding models linked to categories of disability is inequitable with many students missing out on much needed funds. If a student's disability is not recognised under a certain funding model they will not receive financial assistance. The categorisation of disability underpinning resource allocation is controversial as it leads to labelling and othering, which contradicts inclusive education philosophies (Sharma, Forlin, \& Furlonger, 2015; Banks \& McCoy, 2011) Furthermore, as a result of education being the responsibility of individual states and territories, there are issues of national inconsistencies in defining disability relative to financial eligibility (Education and Employment References Committee, 2016). This is a pronounced issue with some families relocating in order to facilitate superior support and assistance. (Education and Employment References Committee, 2016). This highlights the issue of a lack of continuity within the field of education. Bourdieu conceptualises fields as arenas of social relations which are characterised by constant struggles (Agbenyega et al., 2015; Bourdieu, 1990). Across the field of education in Australia, an individual's geographical location can substantially affect the operation of social success. This is a variable which for the most part is out of the control of many individuals, thereby highlighting how inconsistencies across the field of education can create an inequitable landscape for certain students.

\section{The utility of education:}

There are challenges in defining the utility of education for students with disability (Education and Employment References Committee, 2016; ARACY, 2013; Forlin \& Chambers, 2013). As a result, it is difficult to measure the successful application of inclusive education with continuity across the nation, as there is no clear conception of the value of "what is" being measured (Berlach \& Chambers, 2010, p. 52). This comes with a plethora of educational difficulties (Lanacaster, 2014), notably, this lack of clarity makes the process of obtaining educational success for students with disability difficult. Bourdieu (1990) uses the analogy of games to describe the process of obtaining success within social and institutional fields. The analogy of games is useful within Bourdieu's theory demonstrating "his belief that the location of power and influence within human activity is relational" (Blackmore \& Hodgkins, 2012, p. 70). The rules of the 'educational game' relative to one's habitus and capital within fields determine how success is obtained. However, within an institutional field such as education, without clarity as to the value of outcomes, the game of success is extremely difficult to play as the application of the rules are uncertain. This sentiment is mirrored by the Education and Employment References Committee (2016) who state, "Australia, as a nation, has allowed educational outcomes for students with disability to be poor as a consequence of failing to consider what outcomes we want for children with disability" (p. 6). This highlights issues of equity within this field, whereby the clarity of values of education differ 
between certain students, which in turn may be argued to alter the clarity of the practice of how to obtain educational value through outcomes.

A lack of clarity in defining the utility of education for students with disability can make participating in the educational game difficult. However, it may further be argued this lack of clarity causes issues in determining if these students are actually participants in this game at all. As a result of a lack of clarity as to the value of education for students with disability, "the standard of educational accountability for students with disability appears substantially less than for the regular student body" (ARACY, 2013, p. 29). This lack of accountability is prevalent all the way from policy to the classroom (Dempsey \& Davies, 2013; Foreman \& Arthur-Kelly, 2008). The Education and Employment References Committee (2016) claim this issue can be magnified to the point where some students' education can better be described as babysitting. This can be influenced by how classroom teachers use their habitus to situate themselves within the game relative to certain students. Bourdieu (1991) states, "the lines of action suggested by habitus may very well be accompanied by a strategic calculation of costs and benefits" (p. 31). Thereby, the value of a student's education within the field may determine a classroom teacher's disposition to the value they place on educating certain students over others in relation to how the teacher perceives their own success within the field. However, this comes at a great cost to students with disability, whose opportunities for future prosperity are vastly reduced as a result of this approach to their education (The Education and Employment References Committee, 2016; Lamb et al., 2015). It is inappropriate to assume all students will be able to achieve the same goals and outcomes under a single paradigm of education (ARACY, 2013). However, within an equitable paradigm of education the value and utility relative to the goals and outcomes of education should be viewed consistently across the entire student body, allowing all students to participate in the 'educational game of success.'

\section{Conclusion}

It would appear from our analysis of these reports there are areas of concern in Australia in the genuine educational inclusion of students with disability. Genuine educational inclusion must consider and acknowledge a culmination of multiple and complex social variables (Education and Employment References Committee, 2016; ARACY, 2013). However, if the relational structures of power operate in such a manner which create inconsistencies across an educational field, the outcomes of the alignment of social variables will differ relative to positioning within that field. Within the field of education examples of these variables include geographical location, school culture, a family's social and cultural background, a family's socio-economic status, and levels of effective communication between all the stakeholders concerned with a student's education, including the students themselves (Education and Employment References Committee, 2016; ARACY, 2013). In many instances these variables are beyond the control of students and their families, and thereby their value relative to their alignment is vulnerably dependent on positioning with the field.

These inconsistencies appear to demonstrate a lack of continuity across the field of education which may diminish levels of educational inclusion for students with disability. This research was limited to three documents, thereby wider research is needed to identify the relationship between education outcomes and the lack of continuity across the field of education. Our analysis identified that this lack of continuity renders the field of education as being inequitable. This is due to the social and institutional variables within the field of education being vast and ambiguous, making the determining of the value of capital, the operation of habitus, and rules of the 'educational game of success' difficult to ascertain. As 
a result, students with disability may become educationally disadvantaged, which in turn can negatively affect their future prosperity.

Our analysis identified three themes consistent across all three documents. In insolation each one of these themes appear to be cause for concern. However, when these themes are viewed together their complexities are multiplied. Our analysis demonstrates access to a genuine inclusive education for students with disability must negotiate cultural issues, economic capital, and issues in defining the utility and value of education. All of these issues operate at multiple and complex levels within society across the field of education, and thereby how they align from student to student can be extremely inconsistent. We acknowledge the field of education to be extremely complex, and thereby in future research, further variables must be addressed beyond those raised in this paper. 


\section{References}

Agbenyega, J. S., \& Kilbthong, S. (2013). Whole school initiatives: Has inclusion gone astray? International Journal of Whole Schooling, 9(1), 3-22. Agbenyega, J. S., \& Kilbthong, S. (2013). Whole school initiatives: Has inclusion gone astray? International Journal of Whole Schooling, 9(1), 3-22.

Agbenyega, J. S., \& Kilbthong, S. (2015). Re-imagining inclusive research and practice: A focus on Bourdieu's concepts of habitus, capital, doxa and field. In P. Jones \& S. Danforth (Eds.), Foundations of inclusive education research (international perspectives on inclusive education, volume 6) (pp. 66-73). Bingley: Emerald Group.

Ainscow, M., Dyson, A., Goldrick, S., \& West, M. (2011). Developing equitable education systems. Abingdon, UK: Routledge.

Andrews, L., Higgins, A., Andrews, M. W., \& Lalor, J. G. (2012). Classic grounded theory to analyse secondary data: Reality and reflections. The Grounded Theory Review, 11(1), 12-26.

Angwin, J., Blackmore, J., \& Shacklock G. (2001, December). Once you get into the box you can't get out. Paper presented at the Australian Association for Research in Education (AARE) Annual Conference, Perth.

Aron, L., \& Loprest, P. (2012). Disability and the education system. The Future of Children, 22(1), 97-122. doi: 10.1353/foc.2012.0007.

Australian Curriculum, Assessment and Reporting Authority (ACARA). (2012). Curriculum, assessment and reporting in special educational needs and disability: A thematic overview of recent literature, research report. Sydney. Retrieved from: http://www.acara.edu.au/_resources/ACARA_Research_for_Publication_Final.pdf.

Australian Research Alliance for Children and Youth (ARACY) (2013). Inclusive education for students with disability: A review of the best evidence in relation to theory and practice, authored by Forlin, C., Chambers, D., Loreman, T., Deppeler, J., \& Sharma, U. Research report for the Australian Government Department of Education, Employment and Workplace Relations. Canberra. Retrieved from: http://www.aracy.org.au/publicationsresources/command/download_file/id/246/filename/Inclusive_education_for_students_ with_disability_-

A_review_of_the_best_evidence_in_relation_to_theory_and_practice.pdf.

Artiles, A. J. (2011). Toward an interdisciplinary understanding of educational equity and difference: The case of the racialization of ability. Educational Researcher, 40(9), 431445. doi: 10.3102/0013189X11429391.

Artiles, A. J. (2015). Beyond responsiveness to identity badges: Future research on culture in disability and implications for Response to Intervention. Educational Review, 67(1), 1-22. doi: 10.1080/00131911.2014.934322.

Balfanz, R., \& Fox, J. (2011). Early warning systems: Foundational research and lessons from the field. Retrieved from http://www.nga.org/files/live/sites/NGA/files/pdf/1110EARLYDROPBALFANZ.PDF.

Banks, J., \& McCoy S. (2011). A study on the prevalence of special educational needs, research report prepared by the Economic and Social Research Unit for the National Council for Special Education. Trim. Retrieved from: https://www.esri.ie/pubs/BKMNEXT198.pdf.

Berlach, R. G., \& Chambers, D. J. (2010). Inclusivity imperatives and the Australian National Curriculum. The Educational Forum, 75(1), 52-65. doi: 10.1080/00131725.2010.528550.

Blackmore, T., \& Hodgkins, S. L. (2012). Discourse of disabled peoples' organisations: Foucault, Bourdieu and future perspectives. In D. Goodley, B. Hughes, \& L. Davis 
(Eds.), Disability and social theory: New Developments and directions (pp. 70-87). Hampshire and New York: Palgrave Macmillan.

Boslaugh, S. (2007). Secondary analysis for public health: A practical guide. New York: Cambridge University Press. doi: 10.1017/CBO9780511618802.

Bourdieu, P. (1976). Marriage strategies as strategies of social reproduction. In R. Forster \& O. Ranum (Eds.), Family and Society (pp. 117-144). Baltimore: John Hopkins Univeristy Press.

Bourdieu, P. (1977). Outline of a theory of practice (R. Nice, Trans.). Cambridge: Cambridge University Press.

Bourdieu, P. (1990). The logic of practice (R. Nice, Trans.). Stanford: Stanford University Press.

Bourdieu, P. (1991). Language and symbolic power (J. B. Thompson, Eds.) (G. Raymond \& M. Adamson, Trans.). Cambridge: Polity.

Bourdieu, P. (1995). Social space and symbolic power. In D. McQuarie (Eds.), Readings in Contemporary Sociologic Theory: From Modernity to Post-modernity (pp. 323-334). Englewood Cliffs, NJ: Prentice-Hall.

Bourdieu, P. (1997). The forms of capital. In A. Halsey, H. Lauder, P. Brown, \& A. S. Wells (Eds.), Education: Culture, economy and society (pp. 46-59). Oxford: Oxford University Press.

Bourdieu, P. (1999). The weight of the world: Social suffering in contemporary society. California: Stanford University Press.

Bourdieu, P. (2000). Participant objectivation: Breaching the boundary between anthropology and sociology-how? Huxley Memorial Lecture, paper presented at the Royal Anthropological Institute, London University College.

Bourdieu, P., \& Wacquant, L. (1992). An invitation to reflexive sociology. Chicago: University of Chicago Press.

Carter, E. W., Austin, D., \& Trainor, A. (2012). Predictors of postschool employment outcomes for young adults with severe disabilities. Journal of Disability Policy Studies, 23(1), 50-63. doi: 10.1177/1044207311414680.

Commonwealth of Australia. (2006). Disability standards for education 2005. Retrieved from: https://docs.education.gov.au/system/files/doc/other/disability_standards_for_educatio n_2005_plus_guidance_notes.pdf.

Cumming, J. J., \& Dickson, E. (2013). Educational accountability tests, social and legal inclusion approaches to discrimination for students with disability: A national case study from Australia. Assessment in Education: Principles, Policy \& Practice, 20(2), 221-239. doi: 10.1080/0969594X.2012.730499.

Dempsey, I., \& Davies, M. (2013). National test performance of young Australian children with additional educational needs. Australian Journal of Education, 57(1), 5-18. doi: 10.1177/0004944112468700.

DiGiorgio, C. (2009). Application of Bourdieuian theory to the inclusion of students with learning/physical challenges in multicultural school settings. International Journal of Inclusive Education, 13(2), 179-194. doi: 10.1080/13603110701350622.

Doolan, D. M., \& Froelicher, E. S. (2009). Using an existing data set to answer new research questions: A methodological review. Research and Theory for Nursing Practice: An International Journal, 23(3), 203-215. doi:10.1891/1541-6577.23.3.203.

Education and Employment References Committee. (2016). Access to real learning: The impact of policy, funding and culture on students with disability, research report prepared for the Australian Senate. Canberra. Retrieved from: http://www.aph.gov.au/Parliamentary_Business/Committees/Senate/Education_and_E mployment/students_with_disability/Report. 
Foreman, P., \& Arthur-Kelly, M. (2008). Social justice principles, the Law and research, as bases for inclusion. Australasian Journal of Special Education, 32(1), 109-124. doi: 10.1080/10300110701839964.

Forlin, C., \& Chambers, D. (2013). Inclusive education for students with disability part two: A review of the non-government sector in Australia, research report prepared by the Australian Research Alliance for Children and Youth (ARACY) for the Australian Government Department of Education, Employment and Workplace Relations. Canberra.

Gillborn, D., \& Youdell, D. (2000) Rationing Education. Buckingham: Open University Press.

Gonski, D., Boston, K., Greiner, K., Lawrence, C., Scales, B., \& Tannock, P. (2011). Review of funding for schooling: Final Report, research report. Canberra: Department of Education, Employment and Workplace Relations. Retrieved from: https://docs.education.gov.au/system/files/doc/other/review-of-funding-for-schoolingfinal-report-dec-2011.pdf.

Graham, L. (2012) Disproportionate over-representation of Indigenous students in New South Wales government special schools. Cambridge Journal of Education, 42(2), 163-176. doi: 10.1080/0305764X.2012.676625.

Graham, L., \& Slee, R. (2008). Inclusion? In S. Gabel \& S. Danforth (Eds.), Disability and the politics of education: An international reader (pp. 81-99). New York: Peter Lang.

Grenfell, M. (Ed.). (2012). Pierre Bourdieu: Key concepts. Durham: Acumen Publishing Limited.

Kenway, J. (2013). Challenging inequality in Australian schools: Gonski and beyond. Discourse: Studies in the Cultural Politics of Education, 34(2), 286-308. doi: 10.1080/01596306.2013.770254.

Lamb, S., Jackson, J., Walstab, A., \& Huo, S. (2015). Educational opportunity in Australia 2015: who succeeds and who misses out, research report prepared by the Centre for International Research on Education Systems for the Mitchell Institute. Melbourne. Retrieved from: http://www.aspa.asn.au/wp-content/uploads/2015/05/Educationalopportunity-in-Australia-2015-Who-succeeds-and-who-misses-out.pdf.

Lanacaster, J. (2014). School and class room indicators of inclusive education. In C. Forlin \& T. Loreman (Eds.) Foundations of inclusive education research (international perspectives on inclusive education, volume 3) (pp. 227-245). Bingley: Emerald Group.

Lareau, R., \& McNamara Horvat, E. (1999). Moments of social inclusion and exclusion race, class, and cultural capital in family-school relationships. Sociology of Education, 72(1), 37-53. doi: 10.2307/2673185.

Loreman, T., Forlin, C., Chambers, D., Sharma, U., \& Deppeler, J. (2014). Conceptualising and measuring inclusive education. In C. Forlin \& T. Loreman (Eds.) Foundations of inclusive education research (international perspectives on inclusive education, volume 3) (pp. 3-17). Bingley: Emerald Group.

Miles, A. (2016). Overrepresentation in special education: Does the idea violate the equal Protection clause? Rutgers Race and Law Review, 17(2), 245-265.

Mittler, P. (2012). Overcoming exclusion: Social justice through education. Abingdon, UK: Routledge.

Mitra, S., Posarac, A., \& Vick, B. (2013). Disability and poverty in developing countries: A multidimensional study. World Development, 41, 1-18. doi: 10.1016/j.worlddev.2012.05.024.

O'Rourke, J. (2015). Inclusive schooling: if it's so good- why is it so hard to sell? International Journal of Inclusive Education, 19(5), 530-546. doi: 10.1080/13603116.2014.954641.

Sharma, U., Forlin, C. \& Furlonger, B. (2015). Contemporary models of funding inclusive education for students with Autism Spectrum Disorder, research report prepared for the Program for Students with Disabilities (PSD) Review Unit of the Department of 
Education and Training for the State of Victoria. Melbourne. Retrieved from: http://www.education.vic.gov.au/Documents/about/department/psdlitreview_Fundingln clusiveEducationforStudentswithASD.pdf.

Skiba, R. J., Artiles, A. J., Kozleski, E. B., Losen, D. J., \& Harry, E. G. (2016). Risks and consequences of oversimplifying educational inequities: A response to Morgan et al. (2015). Educational Researcher, 45(3), 221-225. doi: 10.3102/0013189X16644606.

Slee, R. (2001). Driven to the margins: Disabled students, inclusive schooling and the politics of possibility. Cambridge Journal of Education, 31(3), 385-397. doi: 10.1080/03057640120086620.

Slee, R. (2008). Beyond special and regular schooling? An inclusive education reform agenda. International Studies in Sociology of Education, 18(2), 99-116. doi: 10.1080/09620210802351342.

Slee, R. (2013). How do we make inclusive education happen when exclusion is a political predisposition? International Journal of Inclusive Education, 17(8), 895-907. doi: 10.1080/13603116.2011.602534.

Sullivan, A. (2002). Bourdieu and education: how useful is Bourdieu's theory for researchers? The Netherlands' Journal of Social Science, 38(2), 144-166.

Sullivan, A. (2007). Cultural capital, cultural knowledge and ability. Sociological Research Online, 12(6), 1. doi: 10.5153/sro.1596.

United Nations Educational, Scientific and Cultural Organization (UNESCO). (2014). Teaching and learning: Achieving quality for all, research report, Paris. Retrieved from: http://www.uis.unesco.org/Library/Documents/gmr-2013-14-teaching-and-learningeducation-for-all-2014-en.pdf.

United Nations Educational, Scientific and Cultural Organization (UNESCO). (2015a). The right to education for persons with disabilities, research report, Paris. Retrieved from: http://unesdoc.unesco.org/images/0023/002325/232592E.pdf.

United Nations Educational, Scientific and Cultural Organization (UNESCO). (2015b). Education for all 2000-2015: Achievements and challenges, research report, Paris. Retrieved from: http://unesdoc.unesco.org/images/0023/002322/232205e.pdf.

United Nations Educational, Scientific and Cultural Organization (UNESCO). (2016). Inclusion in Education. Retrieved from: http://www.unesco.org/new/en/education/themes/strengthening-educationsystems/inclusive-\%20education/.

United Nations. (2006). Convention on the rights of persons with disability. Retrieved from: http://www.un.org/esa/socdev/enable/rights/convtexte.htm\#convtext.

US Department of Education. (2004). Individuals with Disabilities Education Improvement Act. Washington, DC: US Department of Education. Retrieved from: http://www.asha.org/uploadedFiles/advocacy/federal/idea/Rprt108779IDEAconf.pdf. Wacquant, L. (1989). Towards of reflexive sociology: A workshop with Pierre Bourdieu. Sociology Theory, 7(1), 26-63.

Whitburn, B. (2014). The "inclusion" of students with vision impairments: Generational perspectives in Australia. International Journal of Whole Schooling, 10(1), 1-18. 


\section{Biographical Notes}

Luke Macaulay is a PhD candidate and lecturer in inclusive education within the faculty of education at Monash University. Luke Macaulay's research explores inclusive education with a focus on the educational experience of students diagnosed with ASD, including access, participation, and support.

Professor Joanne Deppeler is Associate Dean of Graduate Research in the Faculty of Education at Monash University. Professor Deppeler has extensive experience in leading inclusive education research across different sectors in Australia and in a number of international contexts. In particular, her work has focused on the examination and development of effective practices of teaching and learning with diverse students and practitioner research.

Dr Joseph Agbenyega is a senior lecturer within the faculty of education at Monash University. Joseph Agbenyega's research interests focus on the improvement of inclusive practices in early childhood and middle years, social inclusion, child development and safety, and teacher professional inquiry. 